\title{
Desempenho e qualidade dos ovos de poedeiras semipesadas alimentadas com dietas contendo óleos de soja e canola
}

\author{
Fernando Guilherme Perazzo Costa ${ }^{1}$, Cristóvão Joaquim de Souza ${ }^{2}$, Cláudia de Castro \\ Goulart $^{3,4}$, Raul da Cunha Lima Neto ${ }^{3}$, Janaine Sena da Costa ${ }^{5}$, Walter Esfrain Pereira ${ }^{6}$
}

\footnotetext{
${ }^{1}$ Departamento de Zootecnia/CCA/UFPB, Areia-PB.

2 Curso de Agronomia/CCA/UFPB, Areia-PB.

${ }^{3}$ Curso de Doutorado Integrado em Zootecnia/CCA/UFPB, Areia-PB.

${ }^{4}$ Curso de Zootecnia/CCAB/UVA, Sobral-CE, Bolsista da Funcap.

${ }^{5}$ Curso de Graduação em Zootecnia/CCA/UFPB, Areia - PB.

${ }^{6}$ Departamento de Ciências Fundamentais/CCA/UFPB, Areia-PB.
}

RESUMO - Objetivou-se analisar a influência da adição de níveis crescentes de óleo de soja e canola sobre os índices de desempenho e qualidade interna e externa dos ovos de poedeiras comerciais semipesadas da linhagem Bovans Goldline durante cinco períodos de 28 dias. Foram utilizadas 280 aves com 18 semanas de idade, em um delineamento inteiramente casualizado, com sete tratamentos em um esquema fatorial $2 \times 3+1$ (dois tipos de óleo e três níveis de óleo mais um testemunha adicional) com cinco repetições e oito aves por unidade experimental. Os níveis de óleo de soja e de canola não alteraram o consumo de ração, os pesos dos ovos, de albúmen, de gema e de casca, as porcentagens de albúmen, de gema e de casca e a gravidade específica dos ovos. Houve influência significativa da interação tipo $\times$ nível de óleo sobre a produção de ovos e a conversão por massa e por dúzia de ovos. Com o aumento do nível de óleo de soja, os resultados obtidos para estas variáveis melhoraram, entretanto, a conversão por massa de ovo piorou com o aumento dos níveis de óleo de canola. A adição de óleo de soja promoveu desempenho melhor que o obtido com óleo de canola.

Palavras-chave: aves de postura, óleo de canola, óleo de soja, produção de ovos

\section{Performance and eggs quality in laying hens fed diets with soybean and canola oils}

\begin{abstract}
The objective of this study was to evaluate the influence of soybean and canola oil added in crescent levels on production performance indexes and internal and external egg quality of brown commercial layers of the strain Bovans Goldline during five periods of 28 days. Two hundred and eighty hens with 18 weeks old were distributed in a completely randomized design, with seven diets in a $2 \times 3+1$ factorial arrangement (oil type and oil level, and an additional control), with 5 replicates of 8 hens per experimental unit. The soybean and canola oil levels did not affect the feed consumption; egg, albumen, yolk and shell weights; albumen, yolk and shell percentages, neither the specific gravity. There was an interaction between type and oils levels on egg production and mass conversion and per egg dozen Better results for those characteristics were obtained as soybean oil increased. However, the egg mass conversion was negatively influenced by increase of canola oil. The addition of soybean oil promoted better performance as compared to canola oil.
\end{abstract}

Key Words: canola oil, egg production, laying hen, soybean oil

\section{Introdução}

Óleos e gorduras são ingredientes muito utilizados como fonte concentrada de energia e permitem a formulação de dietas de alta energia para aves. A adição de lipídeos em dietas para frangos de corte tem promovido significativa melhora nas características de desempenho (Dale \& Fuller, 1979, 1980).
A gordura geralmente é introduzida na formulação de rações por seu conteúdo energético. Assim, várias outras vantagens são inicialmente neglicenciadas, embora sejam muito importantes. Segundo Pupa (2004), sob o ponto de vista econômico, é necessário considerar o valor calórico ( 2,25 vezes maior que o de outros alimentos); a economia de ração, em virtude da melhoria na conversão alimentar; a possibilidade de uso de gorduras efetivamente em 
rações de baixo custo; e a maior velocidade de crescimento com abate precoce de animais.

A utilização de gorduras nas rações constitui uma alternativa para períodos de estresse por calor, quando ocorre redução do consumo pelas aves, uma vez que as gorduras aumentam a palatabilidade das rações e possibilitam menor incremento de calor em comparação a proteínas e hidratos de carbono (Church \& Pond, 1988). Além disso, a gordura facilita a absorção de vitaminas lipossolúveis e de importantes pigmentos.

Apesar dos benefícios de sua utilização na dieta (Keshavarrz \& Nakajima, 1995; Rodrigues et al., 2005; Muramatsu et al., 2005), os lipídios contêm ácidos graxos insaturados, susceptíveis à oxidação. Segundo Scott et al. (1982), o processo de oxidação lipídica é a principal causa da perda de qualidade do alimento ou da ração, pois afeta o sabor, o aroma, a cor e textura e resulta na produção de compostos tóxicos reduzindo o valor nutritivo do alimento.

Morita (1992) comparou óleos vegetais e gorduras animais e relatou que o uso de óleos vegetais na avicultura é metabolicamente importante pela riqueza de ácidos graxos insaturados (oléico, linoléico e linolênico). Além disso, são melhor utilizados pelas aves que a gordura animal (mais rica em ácidos graxos saturados).

O óleo de canola tem sido reconhecido como excelente fonte de ácido linolênico (Rowghani et al., 2007). Em virtude dessas suas qualidades, o óleo de canola tem conquistado espaço no mercado ano após ano e inclusive tem sido vendido a preços mais altos (D'Oliveira, 1997). Segundo Furuya et al. (1990), o óleo de canola apresenta aproximadamente 58\% de ácido oléico (C18:1), 22\% de ácido linoléico (C18:2) e 10\% de ácido linolênico (C18:3); seu teor de ácidos graxos poliinsaturados é maior que o dos óleos de amendoim e dendê e menor que o dos óleos de soja, girassol, milho e algodão. Baucells et al. (2000) verificaram que o desempenho produtivo de poedeiras não foi afetado pelo uso de dietas contendo $4 \%$ de óleo de canola, no entanto, houve um acréscimo de ácidos graxos poliinsaturados ômega 3 na gema. Resultados semelhantes foram observados por Pita et al. (2006) ao utilizarem 3\% de óleo de canola.

Como existem poucas pesquisas dedicadas à utilização de óleo de canola em rações para poedeiras e há controvérsias entre os resultados publicados, este trabalho foi conduzido com o objetivo de avaliar o desempenho e a qualidade dos ovos de poedeiras semipesadas submetidas a dietas com diferentes níveis de óleos de soja e canola.

\section{Material e Métodos}

O experimento foi conduzido no Módulo de Avicultura do Departamento de Zootecnia do Centro de Ciências Agrárias da Universidade Federal da Paraíba, Campus II, município de Areia, Paraíba. Foram utilizadas 280 poedeiras da linhagem Bovans Goldline com 18 semanas de idade e peso inicial de $1.520 \pm 110 \mathrm{~g}$. As aves foram distribuídas em um delineamento inteiramente casualizado, com sete tratamentos, em esquema fatorial $2 \times 3+1$, composto pelos tipos de óleo (canola e soja) e pelas doses utilizadas (1, 2 ou 3\%), além de uma dieta controle, em cinco repetições e oito aves por unidade experimental.

As poedeiras foram alojadas em gaiolas de arame com dimensões de $24 \mathrm{~cm} \times 37 \mathrm{~cm} \times 41 \mathrm{~cm}$, com programa de luz natural e água à vontade. As rações - fornecidas uma única vez ao dia, às $7 \mathrm{~h}$, em quantidade de $115 \mathrm{~g} / \mathrm{ave} / \mathrm{dia}$ - foram formuladas à base de milho, farelo de soja, óleos de canola e soja e suplementadas com vitaminas e minerais, segundo recomendações de Rostagno et al. (2000) (Tabela 1).

O experimento foi dividido em cinco períodos de 28 dias, totalizando 140 dias. As aves foram pesadas no início do experimento para padronização do peso por unidade experimental. Em seguida, foram submetidas a um período pré-experimental até que atingissem $90 \%$ de produção. Em cada período, foram avaliados o consumo de ração (g/ave/dia), a produção de ovos (\%), o peso do ovo (g), a massa de ovo (g/ave/dia), as conversões por massa ( $\mathrm{kg} / \mathrm{kg}$ ) e por dúzia de ovos ( $\mathrm{kg} /$ dúzia), os pesos (g) e as porcentagens (\%) de gema, albúmen e casca, a pigmentação da gema e a gravidade específica dos ovos.

Ao final de cada período experimental, foram coletadas as sobras de rações de cada parcela para o cálculo do consumo de ração. A coleta dos ovos foi realizada duas vezes ao dia (10 e $16 \mathrm{~h})$ para registro da freqüência de postura, do número de ovos intactos e defeituosos e da mortalidade das aves.

A produção dos ovos foi calculada em porcentagem dividindo-se a quantidade de ovos produzidos por parcela pelo número de aves. Os ovos dos últimos quatro dias de cada período experimental foram pesados individualmente para obtenção do peso médio. A massa de ovo correspondeu ao produto da produção de ovos e do peso médio dos ovos por parcela. A conversão alimentar por massa de ovo foi calculada por meio da relação entre o consumo de ração e a massa de ovo produzida. A conversão por dúzia de ovos foi calculada como a relação entre o consumo de ração dividida pela produção e seu resultado 
Tabela 1 - Composição percentual das rações experimentais

\begin{tabular}{|c|c|c|c|c|c|c|c|}
\hline Ingrediente & Controle & \multicolumn{3}{|c|}{ Óleo de soja (\%) } & \multicolumn{3}{|c|}{ Óleo de canola (\%) } \\
\hline Milho & 63,000 & 59,945 & 57,750 & 55,097 & 59,938 & 57,722 & 55,061 \\
\hline Farelo de glúten de milho & 6,788 & 3,786 & 1,058 & 0,000 & 3,767 & 1,018 & 0,000 \\
\hline Óleo de soja & 0,000 & 1,000 & 2,000 & 3,000 & 0,000 & 0,000 & 0,000 \\
\hline Óleo de canola & 0,000 & 0,000 & 0,000 & 0,000 & 1,000 & 2,000 & 3,000 \\
\hline Calcário & 8,712 & 8,683 & 8,660 & 8,647 & 8,683 & 8,659 & 8,647 \\
\hline Fosfato bicálcico & 1,506 & 1,486 & 1,479 & 1,481 & 1,486 & 1,479 & 1,481 \\
\hline Sal comum & 0,465 & 0,459 & 0,454 & 0,454 & 0,458 & 0,462 & 0,454 \\
\hline Cloreto de colina $70 \%$ & 0,100 & 0,100 & 0,100 & 0,100 & 0,100 & 0,100 & 0,100 \\
\hline Premix vitamínico ${ }^{1}$ & 0,200 & 0,200 & 0,200 & 0,200 & 0,200 & 0,200 & 0,200 \\
\hline Premix mineral ${ }^{2}$ & 0,050 & 0,050 & 0,050 & 0,050 & 0,050 & 0,050 & 0,050 \\
\hline EM (kcal/kg) & 2.800 & 2.800 & 2.800 & 2.800 & 2.800 & 2.800 & 2.800 \\
\hline PB $(\%)$ & 18,000 & 18,000 & 18,000 & 18,000 & 18,000 & 18,000 & 18,000 \\
\hline Lisina $(\%)$ & 1,191 & 0,849 & 0,925 & 0,959 & 0,849 & 0,927 & 0,959 \\
\hline Metionina+cistina $(\%)$ & 0,682 & 0,702 & 0,701 & 0,701 & 0,702 & 0,686 & 0,701 \\
\hline Metionina (\%) & 0,369 & 0,392 & 0,400 & 0,405 & 0,392 & 0,385 & 0,405 \\
\hline Treonina $(\%)$ & 0,681 & 0,709 & 0,714 & 0,715 & 0,709 & 0,714 & 0,715 \\
\hline Triptofano (\%) & 0,177 & 0,204 & 0,220 & 0,228 & 0,204 & 0,221 & 0,228 \\
\hline Fósforo disponível (\%) & 0,375 & 0,375 & 0,375 & 0,375 & 0,375 & 0,375 & 0,375 \\
\hline Cálcio (\%) & 3,800 & 3,800 & 3,800 & 3,800 & 3,800 & 3,800 & 3,800 \\
\hline
\end{tabular}

multiplicado por 12. Ao final de cada período experimental, separaram-se quatro ovos por parcela para determinação dos pesos e das porcentagens de gema, albúmen e casca. Após separação manual destes componentes, as cascas foram colocadas em estufa a $105^{\circ} \mathrm{C}$ por 2 horas (Silva \& Santos, 2000). A porcentagem foi obtida dividindo-se o peso de cada uma dessas variáveis pelo peso do ovo e, em seguida, multiplicando-se o resultado por 100. A pigmentação das gemas foi identificada por meio do leque colorimétrico da Roche.

A gravidade específica foi determinada pelo método de flutuação salina, conforme metodologia descrita por Hamiltom (1982). Ao final de cada período experimental, foram selecionadas amostras representativas de dois ovos por parcela; em seguida, foram feitas imersões dos ovos em soluções salinas com os devidos ajustes para um volume de 25 litros de água com densidades que variavam de 1,060 a 1,100 com intervalo de 0,0025 . Os ovos foram colocados nos baldes com soluções, da menor para a maior densidade e foram retirados ao flutuarem, sendo registradas as densidades correspondentes às soluções dos recipientes. Antes de cada avaliação, as densidades foram conferidas com densímetro de petróleo.

As análises estatísticas foram realizadas por meio de análise de variância (SAS, 1998). Os contrastes foram testados pelo teste de Dunnett a 5\%, comparando-se o tratamento sem inclusão de óleo (controle) aos demais (1, 2 e 3\% de óleo de soja ou de canola). Em seguida, efetuou-se a análise de regressão para os tratamentos com inclusão dos óleos nas dietas.

\section{Resultados e Discussão}

Verificou-se interação significativa tipo $\times$ níveis de óleo utilizados sobre a produção de ovos e a conversão por massa e por dúzia de ovo (Tabela 2). As aves alimentadas com as rações acrescidas de óleo de soja e com 1 e $3 \%$ de óleo de canola apresentaram maior consumo em comparação àquelas alimentadas com a ração controle, sem óleo, pelo teste Dunnett. No entanto, nas aves alimentadas com as rações acrescidas de óleo, não houve efeito $(\mathrm{P}>0,05)$ do tipo ou do nível de óleo sobre o consumo de ração. 
Tabela 2 - Consumo de ração (CR), produção de ovo (PR), peso do ovo (PO), massa de ovo (MO), conversão por massa de ovo (CAMO) e conversão por dúzia de ovo (CADZ) de poedeiras alimentadas com rações acrescidas de óleo de soja ou de canola

\begin{tabular}{|c|c|c|c|c|c|c|c|}
\hline Variável & & Controle $(0 \%)$ & $1 \%$ & $2 \%$ & $3 \%$ & Média & $\mathrm{CV}$ \\
\hline \multirow[t]{2}{*}{ CR (g) } & Soja & 114,00 & $114,90 *$ & $115,00 *$ & $114,90^{*}$ & 114,93 & 0,43 \\
\hline & Canola & 114,00 & $115,00 *$ & 114,70 & $115,00^{*}$ & 114,90 & \\
\hline \multirow[t]{2}{*}{ PR (\%) } & Soja $^{1}$ & 90,86 & $82,74^{*}$ & 89,79 & 91,70 & 88,08 & 4,05 \\
\hline & Canola & 90,86 & 90,18 & 88,79 & 86,22 & 88,40 & \\
\hline \multirow[t]{2}{*}{ PO (g) } & Soja & 63,29 & 62,93 & 63,77 & 63,52 & 63,41 & 2,47 \\
\hline & Canola & 63,29 & 63,04 & 62,91 & 64,21 & 63,37 & \\
\hline \multirow{2}{*}{ MO (g/ave/dia) } & Soja $^{1}$ & 57,50 & $52,11 *$ & 57,27 & 58,22 & 55,87 & 4,66 \\
\hline & Canola & 57,50 & $56,85^{*}$ & 55,85 & 55,36 & 56,02 & \\
\hline \multirow[t]{2}{*}{ CAMO $(\mathrm{kg} / \mathrm{kg})$} & Soja ${ }^{1}$ & 2,00 & $2,20 *$ & 2,04 & 1,99 & 2,08 & 4,74 \\
\hline & Canola $^{2}$ & 2,00 & 2,03 & 2,07 & 2,16 & 2,09 & \\
\hline \multirow[t]{2}{*}{ CADZ (kg/dúzia) } & Soja $^{1}$ & 1,51 & 1,68 & 1,54 & 1,51 & 1,58 & 4,27 \\
\hline & Canola & 1,51 & 1,54 & 1,56 & 1,61 & 1,57 & \\
\hline
\end{tabular}

$\mathrm{CV}=$ coeficiente de variação; ${ }^{*}=$ Significativo a $5 \%$ de probabilidade pelo teste Dunnett; ${ }^{1}$ Efeito linear a $1 \%$ de probabilidade; ${ }^{2}$ Efeito linear a $5 \%$ de probabilidade.

Os resultados encontrados neste trabalho corroboram os obtidos por Muramatsu et al. (2005), que não encontraram efeito da adição de óleo de soja sobre o consumo de ração. Resultados similares também foram encontrados por Rodrigues et al. (2005), no entanto, Keshavarrz \& Nakajima (1995) observaram que a inclusão de 4\% de lipídios na dieta (mix de gordura animal e vegetal) prejudicou o consumo de ração.

A produção de ovos foi afetada apenas pela dieta com $1 \%$ de óleo de soja, que piorou a produção de ovos em comparação à ração controle. Também foi verificado efeito linear $(\mathrm{P}<0,01)$ dos níveis de óleo de soja sobre a produção de ovos, que não foi influenciada $(\mathrm{P}>0,05)$ pelos níveis de óleo de canola. Verificou-se que, a cada percentual de óleo de soja adicionado, houve aumento potencial de $4,47 \%$ na produção - no nível máximo, a produção foi de $92,53 \%$. Não foi constatado efeito significativo do aumento dos níveis de óleo de canola sobre a produção de ovos, que foi de $88,40 \%$ (Figura 1a).

Rodrigues et al. (2005) observaram que, sem suplementação com óleo de soja à ração, a produção de ovos diminuiu, mas, com a adição de óleo de soja, a produção aumentou e foi maior no nível máximo (8\%) de óleo soja. Resultados diferentes foram relatados por Brugalli et al. (1998) e Muramatsu et al. (2005), que não verificaram efeito dos níveis de óleo sobre a produção de ovos.

Ao fornecerem para poedeiras rações suplementadas com níveis crescentes de óleo de soja, Shafey et al. (1992) não verificaram alteração no consumo de ração e no peso dos ovos. Entretanto, observaram aumento significativo na produção e massa dos ovos em relação às aves alimentadas com a ração controle. Esse aumento da produção de ovos possivelmente está relacionado à melhor utilização da energia da ração suplementada com óleo, em virtude da diminuição do valor calórico.
O peso dos ovos não foi influenciado $(\mathrm{P}>0,05)$ pelo tipo ou pelo nível de óleo. Em estudos realizados por Pita et al. (2004), Rodrigues et al. (2005) e Maramatsu et al. (2005), os níveis de óleo da dieta também não influenciaram o peso dos ovos. Rabello et al. (2003), no entanto, constataram que aves alimentadas com rações com mais de $3 \%$ de óleo de soja produziram ovos mais pesados.

Apenas o óleo de soja, exceto no nível de 1\%, influenciou a massa de ovo, que sofreu efeito linear crescente $(\mathrm{P}<0,01)$ dos níveis de óleo utilizados na dieta (Figura $1 \mathrm{~b}$ ). A cada nível de óleo de soja, a massa de ovo aumenta $3 \mathrm{~g}$, o que resulta em menor produção de ovos, que, apesar de não ter apresentado diferenças significativas, tendeu a reduzir com o aumento dos níveis de óleo de canola na dieta.

A conversão alimentar por massa de ovo das aves alimentadas com a ração contendo $1 \%$ de óleo de soja foi pior que a daquelas alimentadas com a ração controle (Tabela 1). Houve efeito linear dos níveis de óleo da dieta sobre a conversão por massa de ovo, que melhorou com o aumento dos níveis de óleo de soja e piorou com o aumento dos níveis de óleo de canola (Figura 1c).

Essa diferença na conversão por massa de ovo pode estar relacionada às diferenças no conteúdo de energia metabolizável dos óleos. Junqueira et al. (2005), avaliando a utilização de diversas fontes lipídicas em rações para frangos de corte, encontraram valor de energia metabolizável aparente corrigida (EMAn) para o óleo de canola de $8.129 \mathrm{kcal} / \mathrm{kg}$, bem inferior ao obtido para o óleo de soja $(9.201 \mathrm{kcal} / \mathrm{kg})$, cujos coeficientes de metabolização da energia bruta foram de 84,42 e $93,25 \%$, respectivamente. Os autores atribuíram esse fato à presença de ácido erúcico, visto que os cromatogramas do óleo de canola revelaram a existência deste ácido graxo em quantidades superiores a $2 \mathrm{mg} / \mathrm{g}$ de óleo. Resultados semelhantes também foram relatados por Sim et al. (1985), que observaram que o ácido 
A

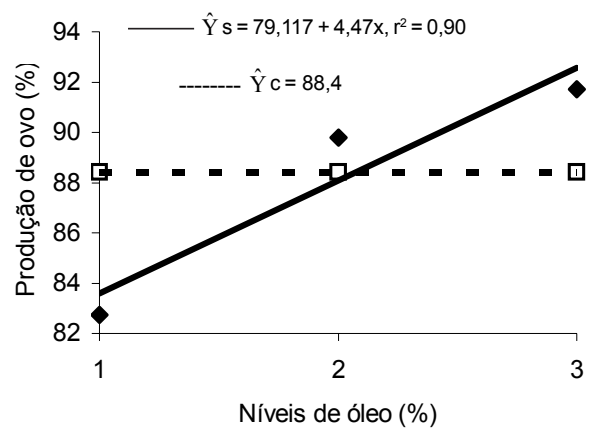

C

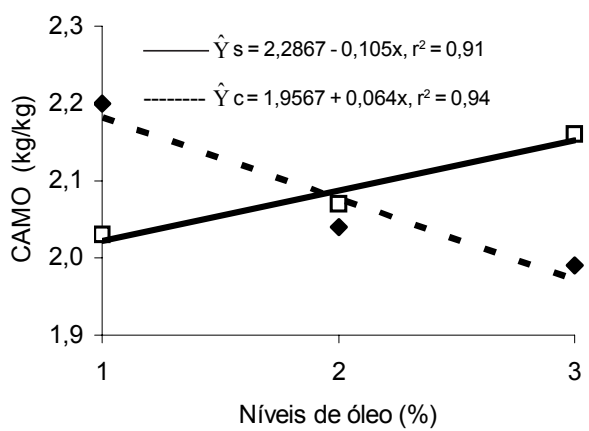

B

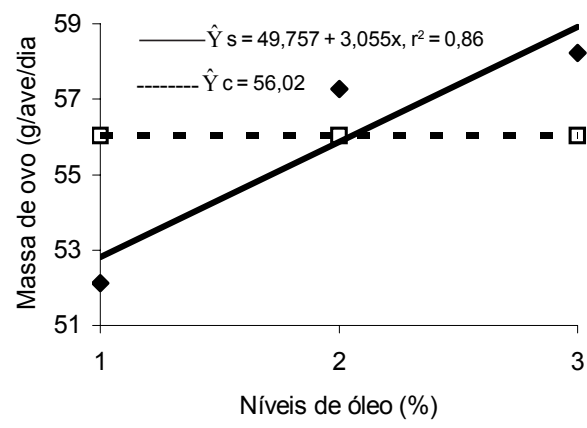

D

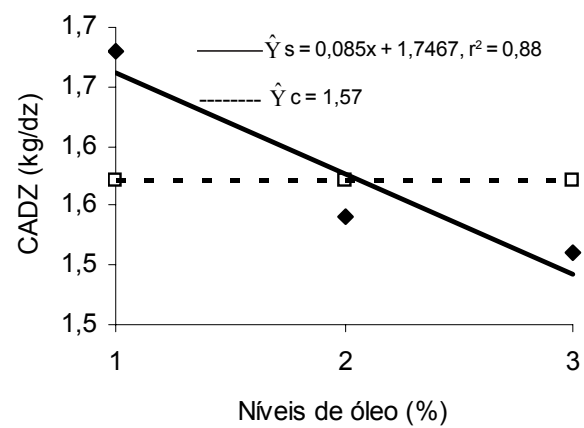

Figura 1 - Produção de ovos (A), massa de ovo (B), conversão por massa de ovo - CAMO (C) e conversão por dúzia de ovo - CADZ (D) de poedeiras alimentadas com rações acrescidas de óleo de soja (vs --) ou canola (vc - - -).

erúcico prejudicou a digestibilidade dos lipídios totais da ração e a digestibilidade individual de seus ácidos graxos.

A conversão por dúzia, no entanto, somente foi influenciada significativamente pelo óleo de soja, que, a cada nível, melhorou em 0,085 a conversão por dúzia (Figura 1d). Esses resultados diferem dos obtidos por Muramatsu et al. (2005) e Rodrigues et al. (2005), que não observaram efeito dos níveis de óleo de soja sobre a conversão por dúzia.

Não houve diferença entre a ração controle e aquelas suplementadas com óleo quando avaliados os pesos de albúmen, gema e casca, as porcentagens de albúmen, gema e casca e a gravidade específica (Tabela 3 ). As aves alimentadas com as rações suplementadas com óleo produziram ovos com gemas menos pigmentadas em comparação àquelas alimentadas com a ração controle, fato provavelmente relacionado à maior porcentagem de milho e farelo de glúten - portanto, mais pigmentos naturais - da ração controle.

Moros et al. (2002), avaliando o teor de xantofilas do milho e de seus subprodutos por cromatografia líquida de alta precisão, observaram que o valor médio de xantofila encontrado para grão de milho amarelo é de $20,09 \mu \mathrm{g} / \mathrm{g}$ de milho. Para o milho opaco, no entanto, esse valor decresce bastante $(0,12 \mu \mathrm{g} / \mathrm{g}$ de milho). Esses autores também observaram que a pigmentação difere entre as regiões do grão de milho. A parte amilácea ou o endocarpo do grão de onde se extrai o farelo de glúten do milho é a porção com maiores teores de xantofilas $(145,91 \mu \mathrm{g} / \mathrm{g}$ de milho), enquanto a parte correspondente ao gérmen de milho possui fração menor desse pigmento $(1,88 \mu \mathrm{g} / \mathrm{g}$ de milho). As xantofilas são substâncias lipossolúveis que, quando depositadas na gema, proporcionam coloração característica, que pode ser maior ou menor de acordo com a quantidade de pigmentantes ingeridos (Silva et al., 2000).

Os níveis e o tipo de óleo utilizado não influenciaram os pesos e as porcentagens de albúmen, gema e casca, a gravidade específica dos ovos e a coloração da gema. Os resultados obtidos nesta pesquisa para essas características do ovo estão de acordo com os descritos por Muramatsu et al. (2005), que não observaram efeito significativo da suplementação de óleo de soja em rações à base de milho e milheto sobre a espessura da casca, os pesos e as porcentagens de albúmen, gema e casca e a gravidade específica dos ovos. Resultados semelhantes foram obtidos por Brugalli et al. (1998), ao adicionarem 0, 2 e 4\% de óleo de 
Tabela 3 - Características dos ovos de poedeiras alimentadas com rações suplementadas com óleo de soja ou de canola

\begin{tabular}{|c|c|c|c|c|c|c|}
\hline Variável & & Controle $(0 \%)$ & $1 \%$ & $2 \%$ & $3 \%$ & $\mathrm{CV}$ \\
\hline \multirow[t]{2}{*}{ Peso de albumen (g) } & Soja & 41,98 & 42,12 & 42,84 & 42,40 & 3,29 \\
\hline & Canola & 41,98 & 42,22 & 42,45 & 42,86 & \\
\hline \multirow[t]{2}{*}{ Peso de gema (g) } & Soja & 16,50 & 16,50 & 16,70 & 16,20 & 3,06 \\
\hline & Canola & 16,50 & 16,60 & 16,10 & 16,30 & \\
\hline \multirow{2}{*}{ Peso de casca (g) } & Soja & 6,17 & 6,25 & 6,25 & 6,14 & 2,74 \\
\hline & Canola & 6,17 & 6,18 & 6,09 & 6,22 & \\
\hline \multirow[t]{2}{*}{ Pigmentação da gema } & Soja & 9,66 & $8,74^{*}$ & $8,22 *$ & $7,94^{*}$ & 2,54 \\
\hline & Canola & 9,66 & $8,97 *$ & $8,42 *$ & $8,08^{*}$ & \\
\hline \multirow[t]{2}{*}{ Albúmen (\%) } & Soja & 64,92 & 64,95 & 65,14 & 65,48 & 1,34 \\
\hline & Canola & 64,92 & 65,07 & 65,65 & 65,52 & \\
\hline \multirow[t]{2}{*}{ Gema $(\%)$} & Soja & 25,56 & 25,39 & 25,35 & 25,04 & 2,89 \\
\hline & Canola & 25,56 & 25,58 & 24,95 & 24,95 & \\
\hline \multirow[t]{2}{*}{ Casca $(\%)$} & Soja & 9,54 & 9,64 & 9,51 & 9,48 & 2,52 \\
\hline & Canola & 9,54 & 9,53 & 9,42 & 9,52 & \\
\hline \multirow[t]{2}{*}{ Gravidade específica $\left(\mathrm{g} / \mathrm{cm}^{3}\right)$} & Soja & 1,0837 & 1,0859 & 1,0843 & 1,0844 & 2,43 \\
\hline & Canola & 1,0837 & 1,0844 & 1,0839 & 1,0846 & \\
\hline
\end{tabular}

$\mathrm{CV}=$ coeficiente de variação; ${ }^{*}=$ Significativo a $5 \%$ de probabilidade pelo teste Dunnett.

soja na dieta de poedeiras semipesadas e por Rodrigues et al.(2005) ao utilizarem $0,2,4,6$ e $8 \%$ de óleo de soja no período de pós-muda e 2 e $4 \%$ na fase de produção.

Entretanto, Rabello et al. (2003) verificaram efeito quadrático dos níveis de óleo de soja $(0,1,2,3$ e $4 \%)$ sobre a porcentagem da casca, que aumentou até o nível de $2 \%$ e reduziu em níveis superiores. Pesquisas comprovam que a adição de óleo em rações para frangos de corte influencia o metabolismo mineral das aves, reduzindo o teor de cinzas ósseas e a retenção de cálcio nos ossos (Dell'Isola et al., 2003), o que está relacionado à formação de sabões insolúveis de ácidos graxos com a presença desses minerais no intestino delgado das aves, o que diminui a absorção intestinal e a retenção de cálcio (Whitehead et al., 1971). Neste estudo o maior nível de óleo estudado parece não ter influenciado a absorção de cálcio, pois as características relacionadas à qualidade externa dos ovos não foram influenciadas significativamente pela suplementação de óleo às dietas.

A suplementação com óleo de canola não influenciou o desempenho e a qualidade dos ovos das aves, mas o aumento dos níveis desse óleo piorou a conversão alimentar por massa de ovo, o que permite afirmar que a inclusão de óleo de canola em rações para poedeiras não é recomendável. A inclusão desse óleo com a finalidade de alterar o perfil de ácidos graxos da gema dos ovos, no entanto, deve ser avaliada em outros estudos, uma vez que pesquisas indicam potencial da utilização desse óleo na modulação da composição dos ácidos graxos dos produtos avícolas (Salmon \& O'Neil, 1973; Hulan et al., 1984; Ajuyah et al., 1991).

Sugere-se, portanto, a realização de mais estudos para análise do potencial do óleo de canola na melhoria do perfil lipídico da gema dos ovos, o que pode agregar valor ao produto e compensar o aumento do custo de produção, decorrente da pior conversão alimentar por massa de ovo.

\section{Conclusões}

A suplementação com óleo de soja em rações para poedeiras promove desempenho melhor que o obtido com óleo de canola.

\section{Literatura Citada}

AJUYAH, A.O.; LEE, K.H.; HARDININ, R.T. et al. Changes in the fatty acid composition of whole carcass and selected meat portions of broiler chickens fed full-fat oil seeds. Poultry Science, v.70, p.2304-2314, 1991.

BAUCELLS, M.D.; CRESPO, N.; BARROETA, A.C. et al. Incorporation of different polyunsaturated fatty acids into eggs. Poultry Science, v.79, p.51-59, 2000.

BRUGALLI, I.; RUTZ, F.; ROLL, V.F.B. Interação entre níveis de gordura e de proteína da dieta sobre a qualidade da casca e desempenho de poedeiras durante o verão. Revista Brasileira de Agrociência, v.4, n.3, p.158-160, 1998.

CHURCH, D.C.; POND, W.G. Basic animal nutrition and feeding. 3.ed. New York: John Wiley and Sons, 1988. p.196199.

D'OLIVEIRA, P.S; PRADO, I.N.; SANTOS, G.T. et al. Efeito da Substituição do farelo de soja pelo farelo de canola sobre o desempenho de novilhas Nelore confinadas. Revista Brasileira de Zootecnia, v.26, n.3, p.568-574, 1997.

DALE, N.M.; FULLER, H.L. Effect of diet composition on feed intake growth of chicks under heat stress. II. Constant us cycling temperature. Poultry Science, v.59, p.1434-1441, 1980.

DELL'ISOLA, A.T.P.; VELOSO, J.A.F.; BAIÃO, N.C. et al. Efeito do óleo de soja em dietas com diferentes níveis de cálcio sobre a absorção e retenção óssea de cálcio e de fósforo em frangos de corte. Arquivo Brasileiro de Medicina Veterinária e Zootecnia, v.55, n.4, p.461-466, 2003.

FURUYA, V.R.B.; HAIASHI, C.; FURUYA, W.M. Farelo de canola na alimentação de Tilápia do Nilo (Oreochromis nilóticos L.) durante o período de reversão do sexo. Revista Brasileira de Zootecnia, v.26, n.6, p.1067-1073, 1997. 
HAMILTOM, R.M.G. Methods and factors that affect the measurement off egg shell quality. Poultry Science, v.61, p.2002-2039, 1982 .

HULAN, H.W.; PROUDFOOT, F.G.; NASH, D.M. The effects of different dietary fat sources on general performance and carcass fatty acid composition of broiler chickens. Poultry Science, v.63, p.324-332, 1984 .

JUNQUEIRA, O.M.; ANDREOTTI, M.O.; ARAÚJO, L.F. et al. Valor energético de algumas fontes lipídicas determinado com frangos de corte. Revista Brasileira de Zootecnia, v.34, n.6, p.2335-2339, 2005 (sup1.).

MATEOS, G.G.; SELL, J.L. Influence of fat and carbohydrate source on rate of foud passage of semipurified diets for layng hens. Poultry Science, v.60, p.2114-2119, 1981.

MORITA, M.M. Custo x benefício do uso de óleos e gorduras em dietas avícolas. In: CONFERÊNCIA APINCO DE CIÊNCIA E TeCnOlogia AVÍCOLA, 1992, Santos. Anais... Santos: Apinco, 1992. p.29-35.

MOROS, E.E.; DARNOKO, D.; CHERYAN, M. et al. Analysis of xanthophylls in corn by HPLC. Journal of Agriculture and Food Chemistry, v.50, n.21, p.5787-5790, 2002.

MURAMATSU, K.; STRINGHINI, J.H.; CAFÉ, M.B. et al. Desempenho, qualidade e composição de ácidos graxos do ovo de poedeiras comerciais alimentadas com rações formuladas com milho ou milheto contendo diferentes níveis de óleo vegetal. Acta Scientarium Animal Science, v.27, n. 1, p. $43-48,2005$.

PITA, M.C.G.; PIBER NETO, E.; NAKAIKA, L.M. et al. Efeito da adição de ácidos graxos insataurados e de vitamina $\mathrm{E}$ à dieta de galinhas e seu reflexo na composição lipídica e incorporação de á-tocoferol na gema do ovo. Brazilian Journal Veterinary Research Animal Science, v.41, n.1, p.25-31, 2004.

PITA, M.C.G.; PIBER NETO, E.; CARVALHO, P.R. et al. Efeito da suplementação de linhaça, óleo de canola e vitamina E na dieta sobre as concentraçãoes de ácidos graxos poliinsaturados em ovos de galinhas. Arquivo Brasileiro de Medicina Veterinária e Zootecnia, v.58, p.925-931, 2006.

PUPA, J.M.R. [2004]. Óleos e gorduras na alimentação de aves e suínos. Revista Eletrônica Nutritime. Disponível em: $<\mathrm{http} / / /$ www.nutritime.com.br/nutritime2/artigos.asp? SESSAO $=$
$2 \& \mathrm{VOLUME}=1 \& \mathrm{NUMERO}=1 \& \mathrm{PERIODO}=\mathrm{Julho} / \mathrm{Ag}$ osto $\&$ $\mathrm{ANO}=2004>$. Acesso em: 8/4/2006.

RABELLO, C.B.V.; PINTO, A.L.; RIBEIRO, H.U et al. Efeito do uso de óleo na ração sobre o desempenho de poedeiras comerciais. In: REUNIÃO ANUAL DA SOCIEDADE BRASILEIRA DE ZOOTECNIA, 39., 2003, Recife. Anais... Recife: Sociedade Brasileira de Zootecnia, 2003. (CD-ROM).

RODRIGUES, E.A.; CANCHERINI, L.C.; JUNQUEIRA, O.M. et al. Desempenho, qualidade da casca e perfil lipídico de gemas de ovos de poedeiras comerciais alimentadas com níveis crescentes de óleo de soja no segundo ciclo, de postura. Acta Scientarium Animal Science, v.27, n.2, p.207-212, 2005

ROSTAGNO, H.S. ; ALBINO, L.F.T.; DONZELE, J.L. et al. Tabelas brasileiras para aves e suínos: composição de alimentos e exigências nutricionais. Viçosa, MG: Editora UFV, 2000. 141p.

ROWGHANI, E.; ARAB, M.; NAZIF, S. et al. Effect of canola oil on cholesterol and fatty acid composition of egg-yolk of laying hens. International Poultry Science, v.6, n.2, p.11-114, 2007.

SALMON, R.E.; O'NEIL, J.B. The effect of the level and source and of a change of source of dietary fat on the fatty acid composition of the depot fat and the thigh and breast meat of turkeys as related to age. Poultry Science, v.52, p.302-314, 1973.

STATISTICAL ANALYSIS SYSTEM - SAS. User's guide: statistics. 6.ed. Cary: SAS Institute, 1998. 578p.

SCOTT, M.L.; NESHEIM, M.C.; YOUNG, R.J. Proteins and amino acids. In: Nutrition of the chicken. 3.ed. Ithaca: M.L. Scott \& Associates, 1982. p.58.

SHAFEY, T.M.; DINGLE, J.B.; McDONALD, M.W. et al. Comparison between wheat, triticale, rye, soybean oil and strain of laying hens on the production, and cholesterol and fatty acid content of eggs. British Poultry Science, v.33, n.2, p.339-346, 1992.

SILVA, J.H.V.; ALBINO, L.F.T.; GODOI, M.J.S. et al. Efeito do extrato de urucum na pigmentação da gema dos ovos. Revista Brasileira de Zootecnia, v.29, n.5, p.1435-1439, 2000.

SILVA, J.H.V.; SANTOS, V.J. Efeito do carbonato de cálcio na qualidade da casca de ovos durante a muda forçada. Revista Brasileira de Zootecnia, v.29, n.5, p.1440-1445, 2000

WHITEHEAD, C.C.; DEWAR, W.A.; DOWNIE, J.N. Effect of dietary fat on mineral retention in the chick. British Poultry Science, v.12, p.249-254, 1971. 